\title{
Minimally invasive transforaminal lumbar interbody fusion with expandable versus static interbody devices: radiographic assessment of sagittal segmental and pelvic parameters
}

\author{
Ammar H. Hawasli, MD, PhD, ${ }^{1,2}$ Jawad M. Khalifeh, BS, ${ }^{1}$ Ajay Chatrath, BS, ${ }^{1}$ \\ Chester K. Yarbrough, MD, ${ }^{3}$ and Wilson Z. Ray, MD ${ }^{1}$
}

Departments of ${ }^{1}$ Neurological Surgery and ${ }^{2}$ Orthopedic Surgery, Washington University School of Medicine, Saint Louis, Missouri; and ${ }^{3}$ Department of Neurosurgery, University of Utah School of Medicine, Salt Lake City, Utah

OBJECTIVE Minimally invasive transforaminal lumbar interbody fusion (MIS-TLIF) has been adopted as an alternative technique to hasten recovery and minimize postoperative morbidity. Advances in instrumentation technologies and operative techniques have evolved to maximize patient outcomes as well as radiographic results. The development of expandable interbody devices allows a surgeon to perform MIS-TLIF with minimal tissue disruption. However, sagittal segmental and pelvic radiographic outcomes after MIS-TLIF with expandable interbody devices are not well characterized. The object of this study is to evaluate the radiographic sagittal lumbar segmental and pelvic parameter outcomes of MIS-TLIF performed using an expandable interbody device.

METHODS A retrospective review of MIS-TLIFs performed between 2014 and 2016 at a high-volume center was performed. Radiographic measurements were performed on lateral radiographs before and after MIS-TLIF with static or expandable interbody devices. Radiographic measurements included disc height, foraminal height, fused disc angle, lumbar lordosis, pelvic incidence, sacral slope, and pelvic tilt. Mismatch between pelvic incidence and lumbar lordosis were calculated for each radiograph.

RESULTS A total of 48 MIS-TLIFs were performed, predominantly at the L4-5 level, in 44 patients. MIS-TLIF with an expandable interbody device led to a greater and more sustained increase in disc height when compared with static interbody devices. Foraminal height increased after MIS-TLIF with expandable but not with static interbody devices. MIS-TLIF with expandable interbody devices increased index-level segmental lordosis more than with static interbody devices. The increase in segmental lordosis was sustained in the patients with expandable interbody devices but not in patients with static interbody devices. For patients with a collapsed disc space, MIS-TLIF with an expandable interbody device provided superior and longer-lasting increases in disc height, foraminal height, and index-level segmental lordosis than in comparison with patients with static interbody devices. Using an expandable interbody device improved the Oswestry Disability Index scores more than using a static interbody device, and both disc height and segmental lordosis were correlated with improved clinical outcome. Lumbar MIS-TLIF with expandable or static interbody devices had no effect on overall lumbar lordosis, pelvic parameters, or pelvic incidence-lumbar lordosis mismatch.

CONCLUSIONS Performing MIS-TLIF with an expandable interbody device led to a greater and longer-lasting restoration of disc height, foraminal height, and index-level segmental lordosis than MIS-TLIF with a static interbody device, especially for patients with a collapsed disc space. However, neither technique had any effect on radiographic pelvic parameters.

https://thejns.org/doi/abs/10.3171/2017.5.FOCUS17197

KEY WORDS minimally invasive lumbar fusion; transforaminal lumbar interbody fusion; expandable cage

ABBREVIATIONS MIS-TLIF = minimally invasive transforaminal lumbar interbody fusion; ODI = Oswestry Disability Index; OP-TLIF = open transforaminal lumbar interbody fusion. 
$\mathrm{M}$ INIMALLY invasive methods in spine surgery are frequently associated with reduced morbidity and shortened recovery when compared with many traditional open techniques. ${ }^{2,4,7,13,17,18}$ Since its inception, minimally invasive transforaminal lumbar interbody fusion (MIS-TLIF) has been the topic of numerous case series, retrospective reviews, and prospective studies. Although many studies report conflicting conclusions regarding short- and long-term outcomes, a meta-analysis of the literature shows some clinical advantages of MISTLIF over traditional open transforaminal lumbar interbody fusion (OP-TLIF) with regards to superior long-term pain scores, reduced blood loss, reduced hospital length of stay, and reduced complication rates. ${ }^{7}$ MIS-TLIF has similar fusion rates to OP-TLIF but a higher amount of radiation exposure than OP-TLIF. ${ }^{7}$ MIS-TLIF also has a lower calculated 2-year cost and accelerated return to work when compared with OP-TLIF. ${ }^{14,15}$ MIS-TLIF technology has evolved to include expandable interbody devices. ${ }^{3,8,11}$ Despite their recent inclusion in the armamentarium available to a minimally invasive spine surgeon, there is a paucity of data on the outcomes associated with these new devices.

Radiographic instrumentation assessment is a method for evaluating surrogate outcomes after MIS-TLIF. There are several radiographic parameters associated with better clinical outcomes in spine surgery. A reduced or collapsed disc and foraminal height are associated with radicular symptoms, pain, and disability. ${ }^{6,21}$ Few studies have evaluated the effects of MIS-TLIF on restoring disc height, and these studies have shown variable results. ${ }^{8,10}$ For deformity surgery, restoring pelvic incidence-lumbar lordosis mismatch to less than $10^{\circ}$ had a great impact on improving clinical performance scores. ${ }^{1,16,19}$ Little is known about the effects of MIS-TLIF with expandable interbody devices on pelvic parameter measurements assessed on lateral radiographs. In light of this, we performed a retrospective review to evaluate the effects of MIS-TLIF with expandable versus static interbody devices on disc height, foraminal height, index-level segmental lordosis, lumbar lordosis, and pelvic parameters.

\section{Methods \\ Patients}

This study is a single-center retrospective review of MIS-TLIF patients. After obtaining IRB approval, basic demographic and operative details were collected on 48 consecutive MIS-TLIFs that were performed by the senior author (W.Z.R.) in 44 patients. Patients were divided into 2 cohorts: patients treated with MIS-TLIF and a static interbody device, or patients treated with MIS-TLIF and an expandable interbody device. Upright lateral radiographs were assessed preoperatively, immediately postoperatively, and on the last follow-up. Oswestry Disability Index (ODI) scores were collected at each visit. The last followup occurred $9.9 \pm 6.5$ months (mean $\pm \mathrm{SD}$ ) (range 0.9-26 months) postoperatively. The last follow-up for static interbody device patients occurred $14.6 \pm 7.1$ months (range 3.0-26.0 months) postoperatively, and the last follow-up for expandable interbody device patients occurred $7.1 \pm$
4.2 months (range 0.9-19.8 months) postoperatively ( $\mathrm{p}<$ $0.01 ; \mathrm{t}(42)=4.3$; $\mathrm{t}$-test). The indications for MIS-TLIF included degenerative disc disease and lumbar spondylosis with radiculopathy with or without Grade I to II spondylolisthesis and the absence of previous surgical instrumentation. The surgeon changed the surgical option from static interbody devices to expandable interbody devices when expandable technology became available. Since its initial use, all patients have received the expandable interbody device.

\section{Operative Technique}

After induction of general anesthesia, the patient was positioned prone and the spine flexed into kyphosis on a modular ProAxis Jackson table (Mizuho). Paramedian incisions over the selected pedicles were made using anterior-posterior fluoroscopy. The MetRx dilator and tubular retractor system (Medtronic) was used to dilate down to the level of the selected bilateral facet complex for MISTLIF. Care was taken to preserve the rostral facet complex. After fluoroscopic level confirmation, the selected facets capsules were cauterized.

Using anterior-posterior fluoroscopy, Tiger Jamshidi needles (Stryker) were inserted into the vertebral pedicles at the selected levels. Percutaneous cannulation of pedicles and vertebral bodies was facilitated with guidewires, and then pedicle screws were inserted under anterior-posterior and lateral fluoroscopy. Tubular retractors were reinserted at the facet overlying the interbody-target disc space. Using an operative microscope, a high-speed bur drill was used to decorticate the facet complex on the nonfacetectomy side. Bur shavings were collected during bilateral facetectomies for use as the autograft.

Attention was turned to the other side for facetectomy. The rostrocaudal extent of the facet complex on the superior articulating process was marked, taking care to leave a portion of the medial facet (inferior articulating process) and pars interarticularis to protect the lateral dura mater and rostral exiting nerve root, respectively (Fig. 1). After drilling down to the level of the disc space, curettes and endplate shavers were used to remove the disc and the cartilage of the entire disc. Care was taken to directly visualize the anterior annulus. After decorticating the endplates, allograft and bone marrow nucleated cell concentrate was packed into the anterior disc space. Subsequently, either a static interbody spacer or an expandable interbody device was filled with the autograft that was collected during the facetectomy and bone marrow nucleated cell concentrate. Twenty-eight of the 29 expandable interbody devices were articulating, expandable "boomerang-style" interbody devices and 1 interbody device was a lordotic-profile "inline" expandable interbody device. The interbody device was then placed and fit into the anterior disc space under fluoroscopic visualization. Segmental lordosis was achieved by 1) expanding the interbody device at the anterior-most part of the disc space and 2) manipulating the modular bed to maximize lumbar lordosis. Anterior and midline placement was verified with anterior-posterior and lateral fluoroscopy. Lordotic pedicle screw rods were inserted percutaneously. The contralateral decorticated facet was packed with autograft/allograft and bone 


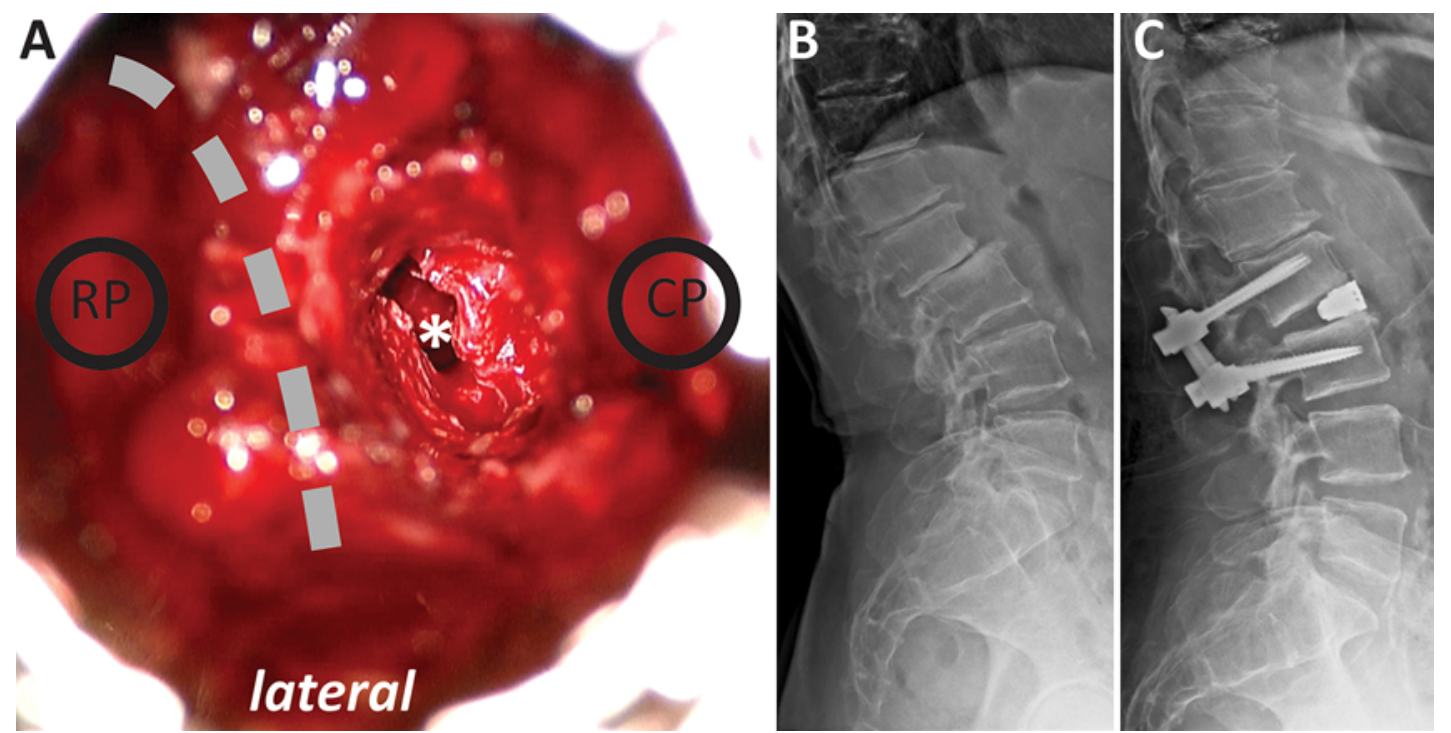

FIG. 1. MIS-TLIF. A: Intraoperative photograph showing a small working channel through a tube after facetectomy and discectomy. The image demonstrates how the exiting nerve root (dashed line) can be protected by keeping the rostral pars interarticularis intact, and the lateral dura can remain covered by the medial superior facet, respectively. Through a small box facetectomy rostral to the caudal pedicle (CP), the disc space (asterisk) can be accessed for a complete discectomy. Through this window, an articulating expandable interbody device can be inserted. B: Preoperative lateral radiograph showing disc collapse and spondylolisthesis at L2-3. C: Postoperative lateral radiograph demonstrating the appearance of an implanted articulating expandable interbody device and restoration of the disc height, increase in foraminal height, and increase in the fused segment angle. RP $=$ rostral pedicle.

marrow nucleated cell concentrate. Wounds were irrigated and closed in routine fashion.

\section{Radiographic Measurements}

Lumbopelvic parameters were measured on upright, lateral 36-inch radiographs or lumbar radiographs. The lumbar radiographs were taken caudally enough to accurately measure the lumbopelvic parameters. Measurements included disc height, foraminal height level, and fused segment angle at the MIS-TLIF level on lateral upright radiographs. Lumbar lordosis, pelvic incidence, sacral slope, pelvic tilt, and pelvic incidence-lumbar lordosis mismatch were also measured. Lateral radiographic measurements were independently performed by 3 authors who did not perform the procedures. Disc space height was measured at the anterior vertebral body from endplate to endplate. To quantify foraminal height, the interpedicular distance was measured as previously described. ${ }^{6}$ Index-level segmental lordosis (i.e., fused segment angle) was measured as the Cobb angle of the superior and inferior endplates at the TLIF level. Lumbar lordosis was measured as the lateral Cobb angle from the superior endplate of L-1 to the superior endplate of S-1. Pelvic incidence, sacral slope, and sacral tilt were measured as previously described..$^{12}$ The absolute difference between the pelvic incidence and lumbar lordosis measurements was calculated for each radiograph. The mean overall disc height among all patients was 0.82 $\pm 0.45 \mathrm{~cm}$. Additional subgroup analysis of the patients with a collapsed preoperative disc space at the index level was performed, excluding patients with a preoperative disc height $>0.81 \mathrm{~cm}$. Postoperative pseudarthrosis was evaluated on each postoperative radiograph. In addition to solid osseous bridging bone, the motion of the fused segments on flexion/extension lateral radiographs, rod breakage, screw failure, lucency around the screws, and interbody subsidence were evaluated. Solid osseous bridging was also assessed on computed topography when available.

\section{Statistical Analysis}

The statistical analysis was performed using MATLAB software for Windows (version R2015; MathWorks). Descriptive statistics in tables are presented as means, standard deviations, frequencies, and percentages. Radiographic measurements are presented as means and standard errors. The effects of MIS-TLIF were calculated using paired and unpaired t-tests with false discovery rate correction for multiple comparisons. Pearson correlation coefficients were calculated between the ODI scores and radiographic measures. Statistical significance was indicated at $\mathrm{p}<0.05$ after multiple comparison correction.

\section{Results \\ Demographics}

Forty-eight MIS-TLIFs were performed in 44 patients (Table 1): 19 with static interbody devices in 16 patients, and 29 with articulating expandable interbody devices in 28 patients. The mean age of the 44 patients was $61.6 \pm$ 9.9 years (range $32.8-79.5$ years). The mean ages of the patients who received static and expandable interbody devices were $57.7 \pm 8.9(32.8-71.8)$ years and $63.9 \pm 9.9$ $(38.8-79.5)$ years, respectively $(\mathrm{p}=0.044 ; \mathrm{t}(42)=-2.08)$. Approximately $63 \%$ of static interbody device patients and $46 \%$ of expandable interbody device patients were female. The majority of MIS-TLIFs were performed at L4-5 for both static (73.7\%) and expandable interbody device (69\%) 
TABLE 1. Demographic characteristics

\begin{tabular}{|c|c|c|c|}
\hline \multirow[b]{2}{*}{ Demographic Data } & \multicolumn{2}{|c|}{ MIS-TLIF Group } & \multirow{2}{*}{$\begin{array}{c}p \\
\text { Value }\end{array}$} \\
\hline & Static Cage & Expandable Cage & \\
\hline No. TLIFs & 19 & 29 & \\
\hline No. of patients & 16 & 28 & \\
\hline Mean age $\pm S D$, yrs & $57.7 \pm 8.9$ & $63.9 \pm 9.9$ & 0.39 \\
\hline Minimum age, yrs & 32.8 & 38.8 & \\
\hline Maximum age, yrs & 71.8 & 79.5 & \\
\hline \multicolumn{4}{|l|}{ Sex, no. $(\%)$} \\
\hline Female & $10(62.5)$ & $13(46.4)$ & 0.52 \\
\hline Male & $6(37.5)$ & $15(53.6)$ & \\
\hline \multicolumn{4}{|l|}{ Level, no. (\%) } \\
\hline L2-3 & $0(0)$ & $4(13.8)$ & \\
\hline L3-4 & $3(15.8)$ & $4(13.8)$ & \\
\hline L4-5 & $14(73.7)$ & $20(69.0)$ & \\
\hline L5-S1 & $2(10.5)$ & $1(3.4)$ & \\
\hline Side of facetectomy, no. (\%) & & & 0.26 \\
\hline Right & $4(21.0)$ & $9(31.0)$ & \\
\hline Left & $12(63.2)$ & $19(65.6)$ & \\
\hline Bilateral & $3(15.8)$ & $1(3.4)$ & \\
\hline
\end{tabular}

cases. Among the patients who received static interbody devices, facetectomies were performed on the left side in $63 \%$ of patients, on the right side in $21 \%$ of patients, and bilaterally in $16 \%$ of patients. Among the patients who received expandable interbody devices, facetectomies were performed on the left side in $66 \%$ of patients, on the right side in $31 \%$ of patients, and bilaterally in $3 \%$ of patients.

\section{MIS-TLIF With an Expandable Interbody Device Increases Disc and Foraminal Heights More Than a Static Interbody Device}

Disc height and foraminal height were measured on lateral, upright, lumbar spine radiographs before and after MIS-TLIF to quantify the indirect decompression pro- duced by MIS-TLIF. MIS-TLIF with a static interbody device produced a short-lasting increase in disc height, but MIS-TLIF with an expandable interbody device produced greater immediate and long-lasting increases in disc height (Fig. 2A, Table 2). With a static interbody device, disc height increased from $0.89 \pm 0.36 \mathrm{~cm}$ to $1.20 \pm$ $0.08 \mathrm{~cm}$ immediately after surgery $(\mathrm{p}=0.02 ; \mathrm{t}(15)=-3.63$; paired t-test). On late follow-up, the increase in disc height waned to $1.15 \pm 0.26 \mathrm{~cm}(\mathrm{p}=0.1 ; \mathrm{t}(15)=-2.8)$. MIS-TLIF with an expandable interbody device led to an immediate and long-lasting increase in disc height from $0.78 \pm 0.25$ $\mathrm{cm}$ to $1.61 \pm 0.07 \mathrm{~cm}(\mathrm{p}<0.01 ; \mathrm{t}(26)=-10.1)$ and 1.60 $\pm 0.32 \mathrm{~cm}(\mathrm{p}<0.01 ; \mathrm{t}(26)=-13.2)$, respectively. When directly comparing disc height measurements, immediate disc height was $30.6 \%$ greater for patients with expandable interbody devices than patients with static interbody devices $(\mathrm{p}<0.01 ; \mathrm{t}(46)=-4.4$; unpaired t-test $)$. Disc height on last follow-up was $32.7 \%$ greater in patients with expandable interbody devices than patients with static interbody devices $(\mathrm{p}<0.01 ; \mathrm{t}(46)=-5.1)$.

Change in disc height from baseline was also measured (Fig. 2B). MIS-TLIF with a static interbody device immediately increased the disc height by $0.40 \pm 0.10 \mathrm{~cm}$, and this increase was $0.32 \pm 0.11 \mathrm{~cm}$ on last follow-up. MISTLIF with an expandable device immediately increased disc height by $0.84 \pm 0.08 \mathrm{~cm}(\mathrm{p}=0.02$ vs static interbody device; $\mathrm{t}(41)=-3.3$; unpaired $\mathrm{t}$-test), which persisted on the last follow-up $(0.81 \pm 0.06 \mathrm{~cm} ; \mathrm{p}<0.01$ vs static interbody device; $\mathrm{t}(41)=-4.24)$. Hence, MIS-TLIF with a static interbody device produced a short-lived increase in disc height, but the use of an expandable interbody device produced a larger and longer-lasting restoration of disc height, an indirect measure of rostrocaudal decompression of the nerve roots.

To directly evaluate the effects of MIS-TLIF on neural foramina, the interpedicular distances were measured on lateral upright radiographs before and after surgery (Fig. 2C). MIS-TLIF with a static interbody device had no significant effect on foraminal height immediately postoperatively or at the late follow-up. MIS-TLIF with an ex-
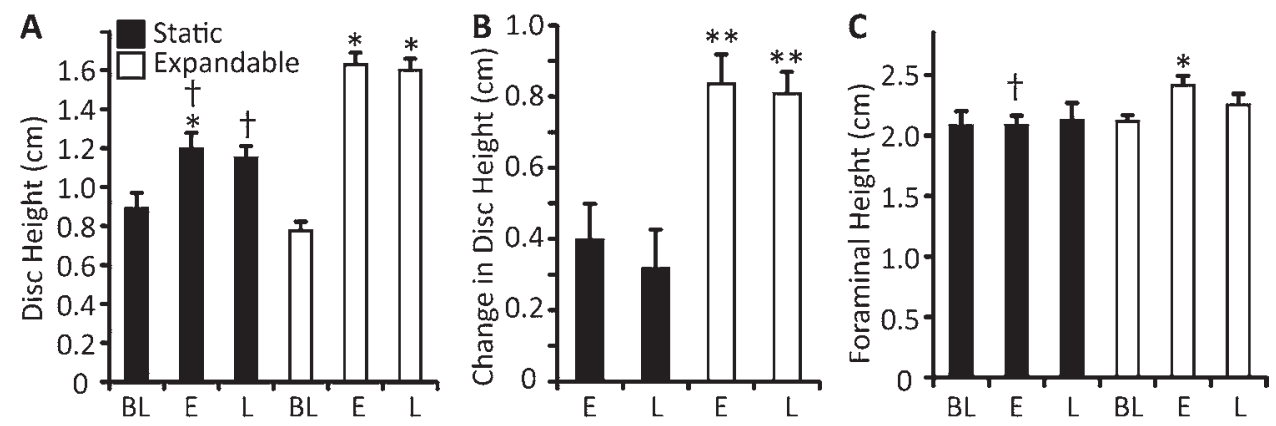

FIG. 2. MIS-TLIF with expandable interbody device increases disc and foraminal heights more than static interbody device. A: MIS-TLIF with an expandable interbody device $(n=29)$ leads to a larger and more sustained increase in disc height when compared with static interbody devices $(n=19)$. B: Change in disc height from baseline immediately postoperative and on distant follow-up demonstrates superior disc height restoration with the expandable interbody device. C: MIS-TLIF with an expandable interbody device, but not a static interbody device, increases foraminal height immediately postoperatively. ${ }^{*} p<0.05$, false discovery rate-corrected paired t-test versus interbody device baseline. ${ }^{* *} p<0.05$ false discovery rate-corrected unpaired t-test versus static interbody device. $\uparrow p<0.05$, false discovery rate-corrected unpaired t-test versus expandable interbody device. Data are shown as the mean $\pm \mathrm{SE}$. $\mathrm{BL}$ = baseline; $\mathrm{E}=$ early measurement immediately postoperative; $\mathrm{L}=$ late follow-up measurement. 


\begin{tabular}{|c|c|c|c|c|c|c|c|c|}
\hline \multirow[b]{3}{*}{ Variable } & \multirow{2}{*}{\multicolumn{2}{|c|}{ Preop† }} & \multirow{2}{*}{\multicolumn{2}{|c|}{ Postop† }} & \multicolumn{4}{|c|}{ p Value ${ }^{*}$} \\
\hline & & & & & \multirow{2}{*}{$\begin{array}{l}\text { Preop Static vs } \\
\text { Expandable }\end{array}$} & \multirow{2}{*}{$\begin{array}{c}\text { Postop } \\
\text { Static vs } \\
\text { Expandable }\end{array}$} & \multirow{2}{*}{$\begin{array}{l}\text { Preop vs } \\
\text { Postop w/ } \\
\text { Static }\end{array}$} & \multirow{2}{*}{$\begin{array}{c}\text { Preop vs } \\
\text { Postop w/ } \\
\text { Expandable }\end{array}$} \\
\hline & Static & Expandable & Static & Expandable & & & & \\
\hline Disc height, $\mathrm{cm}$ & $0.89 \pm 0.36$ & $0.78 \pm 0.25$ & $1.15 \pm 0.26$ & $1.6 \pm 0.32$ & 0.35 & $<0.001$ & 0.1 & $<0.001$ \\
\hline Foraminal height, $\mathrm{cm}$ & $2.08 \pm 0.52$ & $2.12 \pm 0.27$ & $2.13 \pm 0.62$ & $2.25 \pm 0.49$ & 0.86 & 0.57 & 0.9 & 0.3 \\
\hline Segmental lordosis, degree* & $5.8 \pm 3.0$ & $5.8 \pm 4.2$ & $8.1 \pm 3.6$ & $11.0 \pm 4.1$ & 0.99 & 0.03 & 0.2 & $<0.001$ \\
\hline Overall lordosis, degree & $54.3 \pm 15.8$ & $52.2 \pm 12.2$ & $58.7 \pm 8.6$ & $56.9 \pm 11.4$ & 0.6 & 0.09 & 0.1 & 0.2 \\
\hline ODI score & $26.7 \pm 6.9$ & $32.2 \pm 7.97$ & $13.1 \pm 10.1$ & $10.9 \pm 10.5$ & 0.002 & 0.8 & $<0.001$ & $<0.001$ \\
\hline Pseudarthrosis rate, $\%$ & & & 5.30 & 6.90 & & & & \\
\hline
\end{tabular}

* Determined using paired or unpaired multicomparison corrected t-tests.

$\dagger$ Means are presented \pm SE, except for ODI score, which is presented mean \pm SD.

pandable interbody device, however, increased foraminal height from $2.12 \pm 0.05 \mathrm{~cm}$ to $2.41 \pm 0.08 \mathrm{~cm}$ immediately postoperatively $(\mathrm{p}<0.01 ; \mathrm{t}(26)=-3.96$; paired t-test). Immediate foraminal height was $14.8 \%$ greater in patients with expandable interbody devices when compared with patients with static interbody devices $(\mathrm{p}=0.02 ; \mathrm{t}(46)=$ -2.8; unpaired t-test). Foraminal height on late follow-up was $2.25 \pm 0.09 \mathrm{~cm}(\mathrm{p}=0.3 ; \mathrm{t}(26)=-1.42$; paired $\mathrm{t}$-test vs baseline). Therefore, foraminal height increased immediately postoperatively after MIS-TLIF with expandable interbody devices, but not static interbody devices. Hence, MIS-TLIF with an expandable interbody device provides foraminal decompression of the affected nerve roots.

Rather than using the last follow-up, we also evaluated radiographs at equidistant late follow-up times after surgery $(p=0.7)$. These radiographs showed similar findings. Expandable interbody devices were associated with an increase in disc height when compared with baseline ( $\mathrm{p}<0.001)$. Postoperative disc height was greater in patients with expandable interbody devices compared with patients with static interbody devices $(\mathrm{p}<0.001)$. Change in disc height was significantly greater in patients with expandable interbody devices than in patients with static interbody devices $(\mathrm{p}=0.03)$.

\section{MIS-TLIF With an Expandable Interbody Device Increases Index-Level Segmental Lordosis But Has No Effect on Overall Lumbar Lordosis}

To evaluate the effects of modern MIS-TLIF methods on the index-level segmental lordosis (i.e., the fused segment angle), the Cobb angle of the fused segment endplates was measured before and after the procedure. MISTLIF with a static interbody device produced a transient increase in the fused segment angle, while MIS-TLIF with an expandable interbody device produced an immediate and long-lasting increase in the fused segment angle (Fig. $3 \mathrm{~A})$. With a static interbody device, the fused segment angle increased from $5.77^{\circ} \pm 0.68^{\circ}$ to $8.38^{\circ} \pm 0.63^{\circ}$ immediately following surgery $(\mathrm{p}=0.02 ; \mathrm{t}(15)=-3.27$; paired $\mathrm{t}$-test). On the last follow-up, the increase in the angle decreased to $8.09^{\circ} \pm 0.84^{\circ}(\mathrm{p}=0.2 ; \mathrm{t}(15)=-2.17)$. MIS-TLIF with an expandable interbody device led to an immediate and long-lasting increase in the fused segment angle: $5.76^{\circ}$ $\pm 0.77^{\circ}$ to $12.82^{\circ} \pm 0.88^{\circ}(\mathrm{p}<0.01 ; \mathrm{t}(26)=-6.18)$ and $10.99^{\circ} \pm 0.77^{\circ}(\mathrm{p}<0.01 ; \mathrm{t}(26)=-4.68)$, respectively. When directly comparing index-level segmental lordosis, the immediate fused segment angle was $41.9 \%$ greater in patients with expandable interbody devices when compared with patients with static interbody devices $(\mathrm{p}<0.01 ; \mathrm{t}(46)$
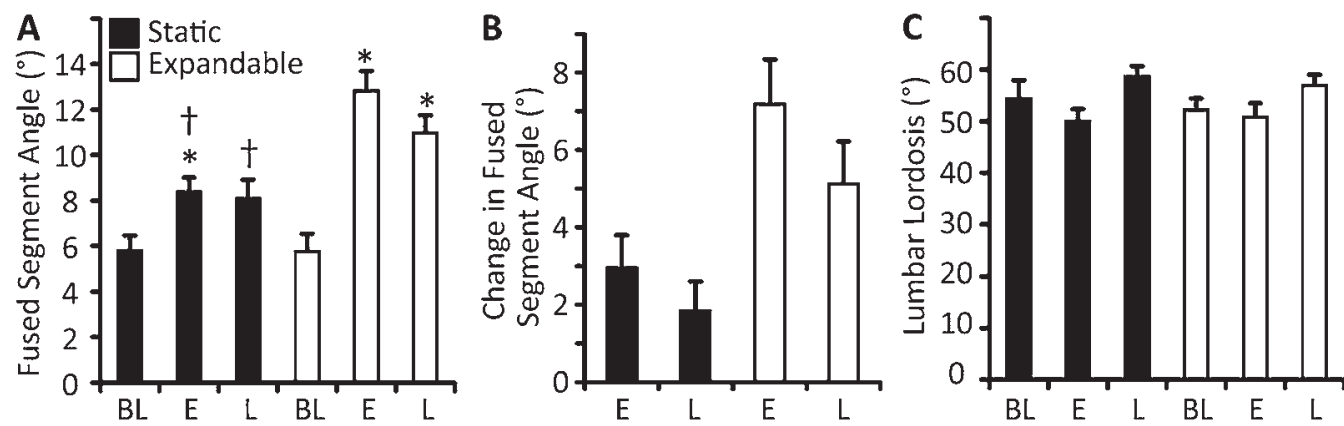

FIG. 3. MIS-TLIF increases the fused segment angle without affecting overall lumbar lordosis. A: MIS-TLIF with a static interbody device provided a transient increase in the fused segment angle (segmental lordosis), but MIS-TLIF with an expandable interbody device provided a long-lasting increase in the fused segment angle (segmental lordosis). B: Trend toward a transient increase in the fused segment angle using MIS-TLIF with an expandable interbody device compared with static interbody devices. C: MISTLIF did not affect overall lumbar lordosis with either interbody device. ${ }^{*} p<0.05$, false discovery rate-corrected paired t-test versus interbody device baseline. $\uparrow p<0.05$, false discovery rate-corrected t-test versus expandable interbody device. Data are shown as the mean $\pm \mathrm{SE}$. $B \mathrm{~L}=$ baseline; $E$ = early measurement immediately postoperative; $\mathrm{L}=$ late follow-up measurement. 
$=-3.70$; unpaired $\mathrm{t}$-test). The fused segment angle on the last follow-up was $30.4 \%$ greater in patients with expandable interbody devices than patients with static interbody devices $(\mathrm{p}=0.03 ; \mathrm{t}(46)=-2.48)$. The change in index-level segmental lordosis from baseline was also measured (Fig. 3B). MIS-TLIF with a static interbody device immediately increased the fused segment angle by $2.95^{\circ} \pm 0.85^{\circ}$, and this increase was $1.84^{\circ} \pm 0.76^{\circ}$ on the last follow-up. MISTLIF with an expandable interbody device increased the fused segment angle by $7.18^{\circ} \pm 1.16^{\circ}$ immediately postoperatively $(\mathrm{p}=0.056$ vs static interbody device; $\mathrm{t}(41)=$ -2.57 ; unpaired t-test) and by $5.13^{\circ} \pm 1.09^{\circ}$ on the last follow-up ( $\mathrm{p}=0.10$ vs static interbody device; $\mathrm{t}(41)=-2.13$; unpaired t-test). Rather than using the last follow-up, we assessed the fused segment angles on the radiographs at equidistant late follow-up times after surgery. Expandable interbody devices showed an increase in the fused segment angle when compared with baseline $(\mathrm{p}<0.001)$. The postoperative fused segment angle was greater for expandable than static interbody devices $(\mathrm{p}<0.001)$. Hence, MISTLIF with a static interbody device produced a transient increase in index-level segmental lordosis, but the use of an expandable interbody device produced a long-lasting restoration of index-level segmental lordosis.

To evaluate the effect of MIS-TLIF on overall lumbar lordosis, the lumbar lordosis sagittal Cobb angle was measured from L1-S1 before and after the procedure. MISTLIF had no significant effects on lumbar lordosis in patients with either static or expandable interbody devices (Fig. 3C). For the static interbody device cohort, baseline overall lumbar lordosis was $54.33^{\circ} \pm 3.62^{\circ}$. Overall lumbar lordosis did not change immediately postoperatively $\left(49.99^{\circ} \pm 2.37^{\circ}\right)$ or at the late follow-up $\left(58.68^{\circ} \pm 1.96^{\circ}\right)$. For the expandable interbody device cohort, baseline overall lumbar lordosis was $52.17^{\circ} \pm 2.26^{\circ}$. Overall lumbar lordosis did not change immediately postoperatively $\left(50.84^{\circ}\right.$ $\left.\pm 2.68^{\circ}\right)$ or at late follow-up $\left(56.89^{\circ} \pm 2.12^{\circ}\right)$. Hence, MISTLIF using an expandable interbody device leads to a long-lasting increase in index-level segmental lordosis without any effect on overall lumbar lordosis.

\section{MIS-TLIF Does Not Affect Pelvic Parameters or Pelvic Incidence-Lumbar Lordosis Mismatch}

To evaluate the effects of MIS-TLIF on pelvic parameters, pelvic incidence, pelvic tilt, and sacral slope were measured on upright lateral radiographs before and after MIS-TLIF. The mismatch between pelvic incidence and lumbar lordosis was also measured before and after MISTLIF. Pelvic incidence is a fixed parameter, and, as expected, MIS-TLIF with either interbody device did not affect pelvic incidence (Fig. 4A). For patients with a static interbody device, baseline pelvic incidence was $57.49^{\circ} \pm 3.34^{\circ}$. Pelvic incidence did not change immediately postoperatively $\left(56.16^{\circ} \pm 3.06^{\circ}\right)$ or at late follow-up $\left(53.92^{\circ} \pm 4.21^{\circ}\right)$. For patients with an expandable interbody device, baseline pelvic incidence was $58.54^{\circ} \pm 2.53^{\circ}$. Pelvic incidence was not affected immediately postoperatively $\left(59.49^{\circ} \pm 2.87^{\circ}\right)$ or at late follow-up $\left(61 \cdot 20^{\circ} \pm 2.44^{\circ}\right)$. MIS-TLIF had no effect on sacral slope (Fig. 4B). For the patients who received a static interbody device, baseline sacral slope was $35.86^{\circ} \pm$ $2.33^{\circ}$. Sacral slope did not change immediately postopera-
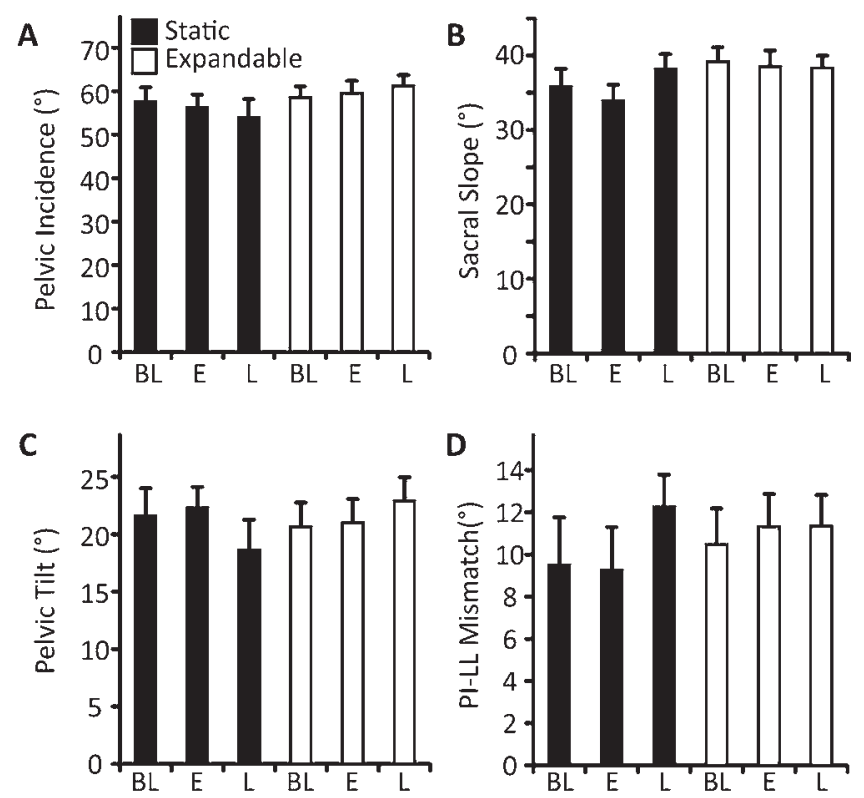

FIG. 4. MIS-TLIF had no significant effects on pelvic parameters with either static or expandable interbody devices. MIS-TLIF had no immediate or lasting effects on pelvic incidence (A), sacral slope (B), pelvic tilt (C), or pelvic incidence-lumbar lordosis mismatch (D). Data represent mean $\pm \mathrm{SE}$. PI-LL = pelvic incidence-lumbar lordosis.

tively $\left(33.86^{\circ} \pm 2.20^{\circ}\right)$ or at late follow-up $\left(38.17^{\circ} \pm 2.00^{\circ}\right)$. For the patients who received an expandable interbody device, baseline sacral slope was $39.20^{\circ} \pm 1.89^{\circ}$. Sacral slope was not affected immediately postoperatively $\left(38.50^{\circ} \pm\right.$ $\left.2.18^{\circ}\right)$ or at late follow-up $\left(38.33^{\circ} \pm 1.62^{\circ}\right)$. MIS-TLIF had no effect on pelvic tilt (Fig. 4C). Preoperative pelvic tilt was $21.63^{\circ} \pm 2.37^{\circ}$ and $20.66^{\circ} \pm 2.10^{\circ}$ in patients with static and expandable interbody devices, respectively. For the patients with a static interbody device, pelvic tilt remained unchanged immediately postoperatively $\left(22.86^{\circ} \pm 1.82^{\circ}\right)$ and at late follow-up $\left(18.60^{\circ} \pm 2.66^{\circ}\right)$. In the expandable interbody device cohort, pelvic tilt did not change immediately postoperatively $\left(20.99^{\circ} \pm 2.08^{\circ}\right)$ or at late follow-up $\left(22.87^{\circ} \pm 2.08^{\circ}\right)$. Finally, MIS-TLIF had no effect on pelvic incidence-lumbar lordosis mismatch (Fig. 4D). For the patients with a static interbody device, baseline mismatch was $9.51^{\circ} \pm 2.26^{\circ}$. Mismatch did not change immediately postoperatively $\left(9.25^{\circ} \pm 2.05^{\circ}\right)$ or at late follow-up $\left(12.26^{\circ}\right.$ $\pm 1.54^{\circ}$ ). For the patients with an expandable interbody device, baseline mismatch was $10.46^{\circ} \pm 1.71^{\circ}$. Mismatch was not affected immediately postoperatively $\left(11.33^{\circ} \pm 1.53^{\circ}\right)$ or at late follow-up $\left(11.34^{\circ} \pm 1.47^{\circ}\right)$. Hence, MIS-TLIF had nominal effects on pelvic parameters, sacral slope, pelvic tilt, and pelvic incidence-lumbar lordosis mismatch when either static or expandable interbody devices were used.

\section{MIS-TLIF in Patients With a Collapsed Disc Space}

We hypothesized that expandable-interbody device technology would restore radiographic parameters most in patients with collapsed disc spaces. Lateral interbody fusions increase segmental lumbar lordosis most in patients with collapsed disc spaces. ${ }^{9}$ Radiographic outcomes were assessed in patients with collapsed disc spaces. The mean 
baseline disc height among all 48 levels was $0.82 \pm 0.45$ $\mathrm{cm}$. Patients with baseline disc heights $<0.81 \mathrm{~cm}$ were selected for further analysis. For patients with a collapsed disc, MIS-TLIF with a static interbody device produced a short-lasting increase in disc height, while MIS-TLIF with an expandable interbody device produced a larger and durable increase in disc height (Fig. 5A). With a static interbody device, disc height increased from $0.57 \pm 0.06 \mathrm{~cm}$ to $1.14 \pm 0.0 .12 \mathrm{~cm}$ immediately after surgery $(\mathrm{p}=0.05 ; \mathrm{t}(6)$ $=-3.49$; paired t-test) and to $1.11 \pm 0.07 \mathrm{~cm}$ on late followup ( $=0.03 ; \mathrm{t}(6)=-4.5)$. MIS-TLIF with an expandable interbody device led to a larger and long-lasting increase in disc height from $0.63 \pm 0.04 \mathrm{~cm}$ to $1.68 \pm 0.07 \mathrm{~cm}$ immediately postoperatively $(\mathrm{p}<0.01 ; \mathrm{t}(16)=-12.1)$ and 1.53 $\pm 0.07 \mathrm{~cm}$ on late follow-up $(\mathrm{p}<0.01 ; \mathrm{t}(16)=-11.0)$. When directly comparing disc height measurements, immediate disc height was $38.8 \%$ greater in patients with expandable interbody devices when compared with patients with static interbody devices $(\mathrm{p}<0.01 ; \mathrm{t}(28)=-4.2$; unpaired t-test). Disc height on last follow-up was $31.5 \%$ greater for expandable interbody devices when compared with static interbody devices $(\mathrm{p}<0.01 ; \mathrm{t}(28)=-3.7)$.

For patients with a collapsed disc, MIS-TLIF with an expandable interbody device, but not a static interbody device, led to a long-lasting restoration of foraminal height (Fig. 5B). MIS-TLIF with a static interbody device in collapsed disc patients did not restore foraminal height immediately postoperatively nor at late follow-up. For MIS-TLIF with a static interbody device, baseline foraminal height was $1.85 \pm 0.18 \mathrm{~cm}$. Foraminal height did not change immediately postoperatively $(2.02 \pm 0.11 \mathrm{~cm} ; \mathrm{p}=$ $0.68, \mathrm{t}(7)=-1.2)$ or on late follow-up $(1.96 \pm 0.21 \mathrm{~cm} ; \mathrm{p}=$ $0.85, \mathrm{t}(7)=0.19)$. MIS-TLIF with an expandable interbody device significantly increased foraminal height from 2.06 $\pm 0.06 \mathrm{~cm}$ to $2.41 \pm 0.08 \mathrm{~cm}$ immediately postoperatively $(\mathrm{p}<0.01 ; \mathrm{t}(16)=-4.1$; paired $\mathrm{t}$-test). Foraminal height on late follow-up increased to $2.34 \pm 0.07 \mathrm{~cm}(\mathrm{p}<0.01 ; \mathrm{t}(16)$ $=-3.5$ ). Immediate foraminal height was $18.5 \%$ greater for expandable interbody devices when compared with static interbody devices $(\mathrm{p}=0.01 ; \mathrm{t}(28)=-3.1$; unpaired $\mathrm{t}$-test $)$. Foraminal height on late follow-up was $18.0 \%$ greater for expandable interbody devices when compared with static interbody devices $(\mathrm{p}=0.07 ; \mathrm{t}(28)=-2.1$; unpaired $\mathrm{t}$-test $)$.

MIS-TLIF with an expandable interbody device in patients with collapsed disc led to a larger and more persistent increase in index-level segmental lordosis than MISTLIF with a static interbody device (Fig. 5C). With a static interbody device, the fused segment angle increased from $3.75^{\circ} \pm 0.77^{\circ}$ to $8.46^{\circ} \pm 1.04^{\circ} \mathrm{cm}$ immediately following surgery $(\mathrm{p}<0.01 ; \mathrm{t}(7)=-5.24$; paired $\mathrm{t}$-test). On the last follow-up, the increase in segmental lordosis waned to $8.06^{\circ} \pm 1.37^{\circ}(\mathrm{p}=0.09 ; \mathrm{t}(7)=-2.94)$. MIS-TLIF with an expandable interbody device led to an early and late increase in the fused segment angle from $3.94^{\circ} \pm 0.67^{\circ}$ to $13.04^{\circ} \pm 1.12^{\circ}(\mathrm{p}<0.01 ; \mathrm{t}(16)=-6.46)$ and $11.74^{\circ} \pm 0.94^{\circ}$ $(\mathrm{p}<0.01 ; \mathrm{t}(16)=-6.89)$, respectively. When directly comparing index-level segmental lordosis, the immediate fused segment angle was $42.6 \%$ greater in patients with expandable interbody devices than patients with static interbody devices $(\mathrm{p}=0.02 ; \mathrm{t}(28)=-2.7$; unpaired t-test). The fused segment angle on the last follow-up was $37.1 \%$ greater in
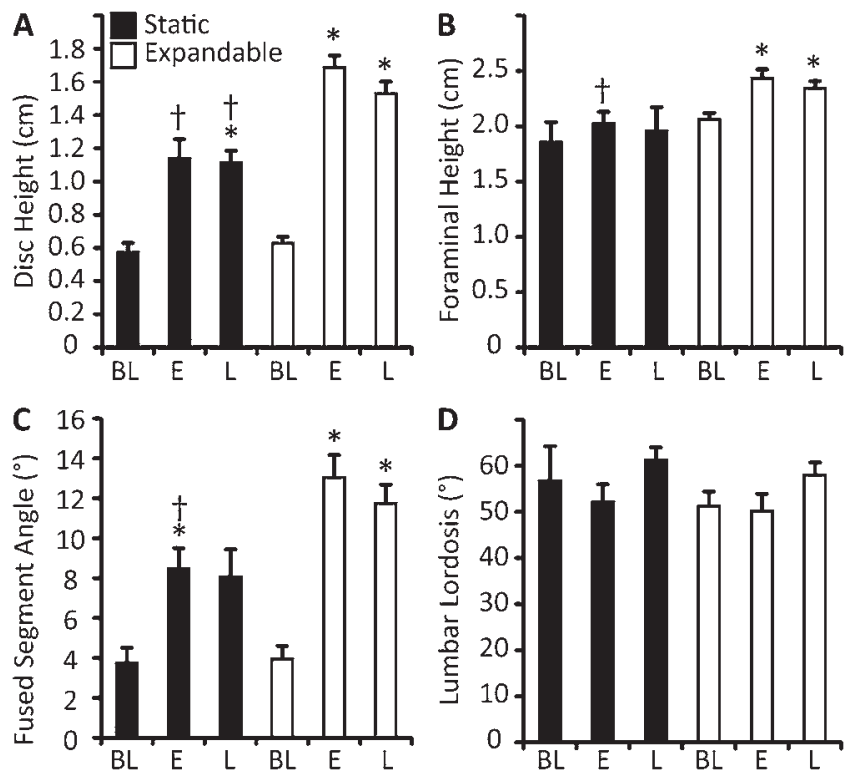

FIG. 5. MIS-TLIF with expandable interbody device restored disc height, foraminal height, and fused segment angle in patients with collapsed disc. A: For patients with a collapsed disc space, MIS-TLIF with an expandable interbody device $(n=19)$ led to a greater restoration in disc height than MIS-TLIF with static interbody devices $(n=11)$. Patients with a collapsed disc space had a baseline disc height < 50th percentile of the whole group. B: MIS-TLIF with an expandable interbody device, but not a static interbody device, led to a long-lasting increase in the foraminal height of the patients with a collapsed disc space. C: MIS-TLIF with expandable interbody device resulted in a more sustained and larger increase in the fused segment angle (segmental lordosis) than with MIS-TLIF with a static interbody device in patients with a collapsed disc. D: MIS-TLIF with either interbody device did not affect overall lumbar lordosis in patients with a collapsed disc. ${ }^{*} p<0.05$, false discovery ratecorrected paired t-test versus interbody device baseline. $\dagger p<0.05$, false discovery rate-corrected unpaired t-test versus expandable interbody device. Data are shown as the mean $\pm \mathrm{SE}$. BL = baseline; $\mathrm{E}=$ early measurement immediately postoperative; $\mathrm{L}$ = late follow-up measurement.

patients with expandable interbody devices than patients with static interbody devices $(\mathrm{p}=0.05 ; \mathrm{t}(28)=-2.28)$.

Lastly, MIS-TLIF with either static or expandable interbody devices in patients with a collapsed disc had no significant effects on lumbar lordosis (Fig. 5D). For the static interbody device cohort, baseline overall lumbar lordosis was $56.68^{\circ} \pm 7.56^{\circ}$. Overall lumbar lordosis did not change immediately postoperatively $\left(52.06^{\circ} \pm 3.92^{\circ}\right)$ or at the late follow-up $\left(61.22^{\circ} \pm 2.75^{\circ}\right)$. For the expandable interbody device cohort, baseline overall lumbar lordosis was $51.14^{\circ} \pm 3.24^{\circ}$. Overall lumbar lordosis did not change immediately postoperatively $\left(50.16^{\circ} \pm 3.71^{\circ}\right)$ or at the late follow-up $\left(58.00^{\circ} \pm 2.71^{\circ} ; \mathrm{p}=0.08 ; \mathrm{t}(16)=-2.25\right.$; paired t-test). Therefore, MIS-TLIF using an expandable interbody device leads to more durable and larger increases in disc height, foraminal height, and index-level segmental lordosis than a MIS-TLIF with a static interbody device in patients with a collapsed disc.

\section{MIS-TLIF With an Expandable Interbody Device Results in Improved ODI Scores}

ODI scores were collected for each patient at baseline 
and on the follow-up visits. The mean preoperative ODI score was higher in the expandable interbody device cohort than the static interbody device cohort $(p=0.002)$ (Table 2). ODI scores decreased significantly in both patients with expandable $(\mathrm{p}<0.001)$ and static interbody devices $(p<0.001)$ after surgery. However, the mean postoperative ODI score was lower in the expandable group than the static group $(\mathrm{p}<0.001)$. Furthermore, the mean change in ODI score was $13.6 \pm 9.1$ for the static interbody device group but $22.3 \pm 12.4$ for the expandable interbody device group $(\mathrm{p}=0.02)$. There was a reverse correlation between ODI score and the fused segment angle $(\mathrm{R}=-0.37$; $\mathrm{p}=$ $0.0009)$ and a reverse correlation between ODI score and disc height $(\mathrm{R}=0.52 ; \mathrm{p}<0.001)$, but not foraminal height $(\mathrm{R}=-0.2 ; \mathrm{p}=0.07)$.

\section{MIS-TLIF With Static and Expandable Interbody Devices Have Similar Pseudarthrosis Rates}

Routine follow-up radiographs were assessed for signs of pseudarthrosis, including motion at the fused segments on flexion/extension lateral radiographs, rod breakage, lucency around screws, and interbody subsidence. Among the 48 levels that underwent MIS-TLIF, 3 of 44 patients (6.8\% of patients) experienced pseudarthrosis $(6.3 \%$ of all levels). There was 1 case of pseudarthrosis among the 19 MIS-TLIFs with static interbody devices (5.3\%) (Table 2) performed on 16 patients $(6.3 \%)$. There were 2 instances of pseudarthrosis in the 29 MIS-TLIFs with expandable interbody devices $(6.9 \%)$ performed on 28 patients $(7.1 \%)$ (Table 2). One of the 3 patients with pseudarthrosis required revision surgery.

\section{Discussion}

Since its first description 14 years ago, ${ }^{5}$ MIS-TLIF and the technologies used in the procedure have evolved and led to improved outcomes in properly selected spine surgery patients. Many initial studies were underpowered or showed mixed results when comparing MIS-TLIF to OPTLIF. Although the majority of reports comparing MISTLIF to OP-TLIF have been observational, retrospective, or single-cohort studies thus far, there is a single small prospective randomized control trial. Wang et al. found the immediate- and long-term visual analog scale scores to be similar in MIS-TLIF and OP-TLIF patients. ${ }^{20}$ Interestingly, Wang et al. showed that the ODI scores were significantly better in MIS-TLIF patients at 3 and 6 months after surgery, but the difference diminished at 1 and 2 years. ${ }^{20}$ An overall meta-analysis has demonstrated superior performance in long-term visual analog scale scores, intraoperative blood loss, hospital length of stay, complication rates, short-term visual analog scale scores, operative duration, and fusion rates for MIS-TLIF compared with OPTLIF, in addition to equal performance on ODI. ${ }^{7}$ Hence, MIS-TLIF appears to offer a satisfactory short- and longterm clinical outcome in properly selected patients.

The radiographic outcomes after MIS-TLIF with modern expandable interbody device technology remain unclear. Radiographic findings can often be surrogate markers for clinical outcomes in regards to measurements of neural decompression and overall balance. A small num- ber of recent studies have evaluated disc and neural foraminal heights in patients with expandable interbody devices. Kim et al. performed a single-cohort study to assess outcomes in 50 patients and reported that MIS-TLIF with an expandable interbody device led to a long-lasting increase in disc height, but only a transient increase in foraminal height. ${ }^{8}$ In this study, we evaluated both segmental measures as well as pelvic parameters on lateral radiographs after MIS-TLIF to compare expandable interbody devices to static interbody devices. Segmental measurements included disc height, foraminal height, and fused segment angle. The global and pelvic parameters used to evaluate overall balance included lumbar lordosis, pelvic incidence, sacral slope, pelvic tilt, and pelvic incidence-lumbar lordosis mismatch.

Similar to Kim et al., ${ }^{8}$ we found that MIS-TLIF with an expandable interbody device produced an immediate and long-standing increase in disc height. MIS-TLIF with static interbody devices led to a $30 \%$ smaller increase in disc height, which was not sustained over time. As reported by other authors, ${ }^{8}$ MIS-TLIF transiently increased foraminal height in our expandable interbody device group. However, we showed that the use of a static interbody device did not increase foraminal height. Each of these measures indicates that MIS-TLIF with an expandable interbody device provides a superior indirect rostral-caudal decompression of the exiting nerve root. Next, we examined how MISTLIF affects index-level segmental lordosis and overall lumbar lordosis. MIS-TLIF with an expandable interbody device led to a greater increase in the fused segment angle than MIS-TLIF with a static interbody device. This increase in the fused segment angle was persistent in patients with expandable interbody devices, but was transient in patients with a static interbody device. Despite the anecdotal emphasis on using MIS-TLIF to restore segmental lordosis and achieve overall lordosis, the data presented here show that neither MIS-TLIF with an expandable interbody device nor MIS-TLIF with a static interbody device affected overall lumbar lordosis. Finally, we evaluated overall pelvic parameters and found that short-segment MIS-TLIF had no effect on pelvic slope or pelvic tilt. The lack of an effect on pelvic incidence-lumbar lordosis mismatch also highlights the limitation of using MIS-TLIF to achieve sagittal balance, or this represents a limitation of this study.

The study also highlights the difference between patients with a relatively normal disc height and patients with a collapsed disc. Lateral interbody fusions are known to increase segmental lumbar lordosis, especially in patients with collapsed disc spaces. ${ }^{9}$ Here, we also showed that patients with a collapsed disc space-defined as a disc space less than the 50th percentile of the whole group-may benefit from the use of an expandable interbody device during MIS-TLIF. By expanding the interbody device at the most anterior portion of the disc space and extending the modular surgical table, a surgeon can maximize postoperative disc height, foraminal height, and index-level segmental lordosis during MIS-TLIF.

This study carries several important limitations. First of all, this is a single-cohort retrospective study with a small number of patients, and therefore this study may be underpowered to detect many changes. The follow-up of 
the patients was not uniformly consistent, further underpowering the study.

\section{Conclusions}

MIS-TLIF with an expandable interbody device led to a larger and longer-lasting increase in disc height, foraminal height, and index-level segmental lordosis than MIS-TLIF with a static interbody device, especially for patients with a collapsed disc space. MIS-TLIF did not affect radiographic pelvic parameters.

\section{Acknowledgments}

Research reported in this publication was supported by the American Association of Neurological Surgeons Neurosurgery Research and Education Foundation Post-Residency Clinical Fellowship Program (awarded to the Department of Neurosurgery, Washington University School of Medicine) and internal funding from the Department of Neurosurgery at Washington University School of Medicine. The funders had no role in the study design, data collection and analysis, decision to publish, or preparation of the manuscript.

\section{References}

1. Aoki Y, Nakajima A, Takahashi H, Sonobe M, Terajima F, Saito M, et al: Influence of pelvic incidence-lumbar lordosis mismatch on surgical outcomes of short-segment transforaminal lumbar interbody fusion. BMC Musculoskelet Disord 16:213, 2015

2. Asgarzadie F, Khoo LT: Minimally invasive operative management for lumbar spinal stenosis: overview of early and long-term outcomes. Orthop Clin North Am 38:387-399, vi-vii, 2007

3. Cannestra AF, Peterson MD, Parker SR, Roush TF, Bundy JV, Turner AW: MIS expandable interbody spacers: a literature review and biomechanical comparison of an expandable MIS TLIF with conventional TLIF and ALIF. Spine (Phila Pa 1976) 41 (Suppl 8):S44-S49, 2016

4. Fessler RG: Minimally invasive percutaneous posterior lumbar interbody fusion. Neurosurgery 52:1512, 2003

5. Foley KT, Lefkowitz MA: Advances in minimally invasive spine surgery. Clin Neurosurg 49:499-517, 2002

6. Hawasli AH, Chang J, Yarbrough CK, Steger-May K, Lenke LG, Dorward IG: Interpedicular height as a predictor of radicular pain in adult degenerative scoliosis. Spine J 16:10701078, 2016

7. Khan NR, Clark AJ, Lee SL, Venable GT, Rossi NB, Foley KT: Surgical outcomes for minimally invasive vs open transforaminal lumbar interbody fusion: an updated systematic review and meta-analysis. Neurosurgery 77:847-874, 2015

8. Kim CW, Doerr TM, Luna IY, Joshua G, Shen SR, Fu X, et al: Minimally invasive transforaminal lumbar interbody fusion using expandable technology: a clinical and radiographic analysis of 50 patients. World Neurosurg 90:228-235, 2016

9. Le TV, Vivas AC, Dakwar E, Baaj AA, Uribe JS: The effect of the retroperitoneal transpsoas minimally invasive lateral interbody fusion on segmental and regional lumbar lordosis. Sci World J 2012:516706, 2012

10. Lee CK, Park JY, Zhang HY: Minimally invasive transforaminal lumbar interbody fusion using a single interbody cage and a tubular retraction system: technical tips, and perioperative, radiologic and clinical outcomes. J Korean Neurosurg Soc 48:219-224, 2010

11. Neely WF, Fichtel F, Del Monaco DC, Block JE: Treatment of symptomatic lumbar disc degeneration with the VariLift-L interbody fusion system: retrospective review of 470 cases. Int J Spine Surg 10:15, 2016

12. O'Brien MF, Kuklo TR, Blanke KM, Lenke LG (eds): Spinal Deformity Study Group Radiographic Measurement Manual. Memphis: Medtronic Sofamor Danek, 2008

13. Ogden AT, Fessler RG: Minimally invasive techniques for lumbar disorders, in Winn HR (ed): Youmans Neurological Surgery, ed 6. Philadelphia: Elsevier, 2011, Vol 3, pp 3109-3113

14. Parker SL, Adogwa O, Bydon A, Cheng J, McGirt MJ: Costeffectiveness of minimally invasive versus open transforaminal lumbar interbody fusion for degenerative spondylolisthesis associated low-back and leg pain over two years. World Neurosurg 78:178-184, 2012

15. Parker SL, Mendenhall SK, Shau DN, Zuckerman SL, Godil SS, Cheng JS, et al: Minimally invasive versus open transforaminal lumbar interbody fusion for degenerative spondylolisthesis: comparative effectiveness and cost-utility analysis. World Neurosurg 82:230-238, 2014

16. Schwab F, Patel A, Ungar B, Farcy JP, Lafage V: Adult spinal deformity-postoperative standing imbalance: how much can you tolerate? An overview of key parameters in assessing alignment and planning corrective surgery. Spine (Phila Pa 1976) 35:2224-2231, 2010

17. Sembrano JN, Tohmeh A, Isaacs R: Two-year comparative outcomes of MIS lateral and MIS transforaminal interbody fusion in the treatment of degenerative spondylolisthesis: part i: clinical findings. Spine (Phila Pa 1976) 41 (Suppl 8):S123-S132, 2016

18. Shunwu F, Xing Z, Fengdong Z, Xiangqian F: Minimally invasive transforaminal lumbar interbody fusion for the treatment of degenerative lumbar diseases. Spine (Phila Pa 1976) 35:1615-1620, 2010

19. Than KD, Park P, Fu KM, Nguyen S, Wang MY, Chou D, et al: Clinical and radiographic parameters associated with best versus worst clinical outcomes in minimally invasive spinal deformity surgery. J Neurosurg Spine 25:21-25, 2016

20. Wang HL, Lü FZ, Jiang JY, Ma X, Xia XL, Wang LX: Minimally invasive lumbar interbody fusion via MAST Quadrant retractor versus open surgery: a prospective randomized clinical trial. Chin Med J (Engl) 124:3868-3874, 2011

21. Watanabe K, Yamazaki A, Morita O, Sano A, Katsumi K, Ohashi M: Clinical outcomes of posterior lumbar interbody fusion for lumbar foraminal stenosis: preoperative diagnosis and surgical strategy. J Spinal Disord Tech 24:137-141, 2011

\section{Disclosures}

Dr. Ray is a consultant for Globus Medical, DePuy/Synthes, and Acera.

\section{Author Contributions}

Conception and design: Hawasli, Ray. Acquisition of data: all authors. Analysis and interpretation of data: Hawasli, Chatrath, Yarbrough, Ray. Drafting the article: Hawasli. Critically revising the article: all authors. Reviewed submitted version of manuscript: all authors. Approved the final version of the manuscript on behalf of all authors: Hawasli. Statistical analysis: Hawasli. Administrative/technical/material support: Ray. Study supervision: Ray.

\section{Correspondence}

Ammar H. Hawasli, Department of Neurosurgery, Washington University School of Medicine, Campus Box 8057, 660 S Euclid Ave., St. Louis, MO 63110. email: hawaslia@wudosis.wustl.edu. 